\title{
La construcción social del mercado laboral doméstico en España a comienzos del siglo XXI
}

\author{
Cristina GARCÍA SAINZ \\ Universidad Autónoma de Madrid \\ Cristina.garcia@uam.es \\ M. Lourdes SANTOS PÉREZ \\ Universidad de Salamanca \\ lula@usal.es \\ Nelcy Y. VALENCIA OLIVERO \\ Universidad Autónoma de Madrid \\ nelcyyolyvalencia@gmail.com
}

Recibido: 17-04-2013

Aceptado: 18-07-2013

\section{RESUMEN}

España es el país de la Unión Europea que cuenta con la cifra más elevada de personal doméstico asalariado. Es también donde más se ha incrementado el servicio doméstico en los últimos años. En la década 19982007 el crecimiento del sector ha sido espectacular, hasta el punto que la cifra de personas asalariadas que desempeñaban esta actividad doméstica remunerada llegó incluso a duplicarse. Las causas de esta evolución se encuentran en distintos factores: estructurales, relacionados con la desigualdad económica y la configuración del mercado de trabajo; coyunturales, referidos a la articulación normativa entre extranjería y empleo doméstico; e institucionales, como el tipo de gestión que distintas entidades llevan a cabo para mediar entre demandas y ofertas de empleo. La investigación empírica realizada sobre la labor de mediación para el acceso al servicio doméstico refleja el modo de construcción de este mercado laboral en el que se dan prácticas de gestión de carácter semiformal que desbordan los usos convencionales. Además de la formación, cualificación o experiencia, que habitualmente se solicitan para buscar empleo, se indaga sobre atributos personales o condiciones extralaborales de las demandantes. La formalización de la relación contractual con frecuencia depende más de estas características que de cualidades profesionales.

Palabras clave: trabajo doméstico remunerado, inmigración, determinantes económicos y normativos, mediación laboral y movilidad ocupacional.

\section{Social Construction of the Domestic Labor Market in Spain at the Beginning of the $21^{\text {st }}$ Century}

\begin{abstract}
Spain is the European Union country which has the highest number of domestic workers. It is also the place where domestic work has increased the most in recent years. Between 1998 and 2007, the growth in this labor sector has been so spectacular that the number of domestic workers even doubled. The reasons for this development can be grouped in different factors: structural factors, such as the inequality of income
\end{abstract}


distribution and characteristics of the labor market; contextual factors, such as the Immigration Law and other laws of domestic work; and institutional arrangements, like the type of management that different entities perform to mediate between job demands and supplies. The empirical research on the work of mediation for accessing domestic work shows the way of construction of this labor market, in which there are practices that go beyond conventional uses. In addition to the training requirements, qualifications or experience, that are usually asked when seeking employment, it explores personal attributes or conditions outside of the work of the applicants. The formalization of the contractual relationship often depends more on these characteristics than of other professional qualities.

Keywords: domestic work. immigration. economic and legal determinants. Labor mediation. Ocupational mobility.

\section{REFERENCIA NORMALIZADA}

García Sainz, C., Santos Pérez, M. L., Valencia Olivero, N.Y. (2014). "La construcción social del mercado laboral doméstico en España a comienzos del siglo XXI". Cuadernos de Relaciones Laborales, Vol. 32, núm. 1, p. 101-131.

SUMARIO: Introducción. 1. Determinantes socioeconómicos del crecimiento del sector doméstico. 1.1. De cómo las desigualdades socioeconómicas intervienen en la generación de empleo doméstico. 1.2. Del modelo productivo, los mercados de trabajo y el empleo doméstico. 2. Normativa de extranjería y legislación laboral del servicio doméstico. 2.1. De cómo la legislación en materia de extranjería condiciona la movilidad social y ocupacional de las inmigrantes. 2.2. De cómo la regulación del trabajo doméstico en España institucionaliza la inestabilidad de las trabajadoras. 3. La intermediación de los programas de empleo en el servicio doméstico. 3.1. De cómo los programas de empleo conducen a sus usuarias hacia el sector doméstico. 3.1.1. La gestación del perfil de las demandantes. 3.1.2 Trayectoria laboral y expectativas de movilidad. 3.1.3. Los hogares ajustan la demanda. 4. A modo de conclusión. Elementos para un debate sobre la sostenibilidad del modelo basado en el servicio doméstico inmigrante. 5. Bibliografía.

\section{Introducción}

El estudio del sector doméstico está alcanzando una creciente importancia, tanto a escala nacional como internacional. Su interés responde al impacto que un conjunto de factores como el envejecimiento de la población, la mayor participación de las mujeres en el empleo y las nuevas formas de convivencia en los hogares, han tenido sobre la tradicional forma de proporcionar cuidados familiares. En España, ni los poderes públicos ni las organizaciones privadas han dado una respuesta satisfactoria a la demanda de cuidados generada por parte de las personas dependientes y sus familias; de ahí que sigan siendo las personas del hogar y especialmente las mujeres quienes, bien asumiendo el trabajo o bien externalizándolo mediante la contratación de cuidadoras inmigrantes, resuelven dicha demanda. El trabajo doméstico remunerado se ha convertido en una estrategia decisiva de la organización doméstica familiar $\mathrm{y}$, sólo en parte, en objeto de atención y regulación desde las políticas públicas.

En tanto que empleo vinculado a la organización social del cuidado, el servicio doméstico se encuentra en la confluencia de las estructuras del mercado de trabajo, la actuación del Estado y las distintas políticas sociolaborales que afectan al desempeño de esta actividad (Razavi y Saab, 2010:451). En sintonía con este enfoque, en este artículo se tratan los factores económicos y sociales, como las 
desigualdades de ingresos y salarios, las políticas sociolaborales, en relación con normativas de inmigración y empleo doméstico, y la labor institucional, que promueve la mediación laboral en el desarrollo del mercado doméstico en España, y especialmente en Madrid, a comienzos del siglo XXI.

En España el empleo doméstico remunerado venía mostrando una tendencia descendente desde mediados del pasado siglo. Es en los últimos años de los noventa cuando este mercado se reactiva y experimenta un significativo crecimiento. $\mathrm{Si}$ décadas atrás el servicio doméstico respondía principalmente a una razón de estatus, donde las familias acomodadas podían mostrar y/o aparentar holgura económica y una posición social acomodada, ahora ese perfil se ha diversificado. No sólo las clases altas disponen de asistenta o empleada del hogar ${ }^{1}$ sino que también algunos sectores de clase media, con suficiente poder adquisitivo, han accedido a contratar mano de obra remunerada para realizar tareas domésticas rutinarias en los hogares y, lo que es más reciente, sectores de población con recursos limitados, buena parte personas mayores que precisan ser cuidadas, han pasado a ser empleadoras de las cuidadoras que les atienden. Como en el pasado, el empleo doméstico sigue siendo una actividad laboral con poco reconocimiento social y mal remunerado; en la actualidad, la novedad de este sector es su composición mayoritaria por mano de obra inmigrante que es contratada para trabajar interna, o por horas, con independencia de que tenga o no su situación de residencia y trabajo regularizada, lo que deja un amplio margen para la discrecionalidad en la relación laboral.

El empleo doméstico representa en España en torno al 5\% de la ocupación. Se trata de una cifra alta, si se compara con la media de los países desarrollados, donde apenas alcanza el 1\% (ILO-OIT, 2013:20). España e Italia reúnen más del cincuenta por ciento de todo el empleo doméstico europeo. En el caso español, es a finales de la última década del pasado siglo cuando el empleo doméstico modifica la tendencia descendente que venía presentando décadas atrás para iniciar una rápida recuperación que se mantiene hasta 2007, cuando se estabiliza para descender después moderadamente. Aunque en términos absolutos la cifra de empleados domésticos cae desde $2008^{2}$, en términos porcentuales la proporción no ha variado prácticamente, ya que en 2007 representaba un 4,6\% del total de la ocupación asalariada y en 2012 alcanza el mismo porcentaje. Esta primera observación mostraría que el sector no se ha visto especialmente afectado por crisis económica; sin embargo, una mirada más precisa no corrobora esa estabilidad en el empleo

${ }^{1}$ Dado que se hace referencia a un grupo de población compuesto en su gran mayoría por mujeres, a lo largo de este artículo se utilizan términos en masculino o en femenino, indistintamente, en sentido genérico.

${ }^{2}$ La cifra más alta de empleo doméstico de las dos últimas décadas se localiza en 2007, cuando alcanza los 770.000 empleados (INE, Encuesta de población activa). Desde ese año hasta 2012 el empleo doméstico se ha reducido en un $17 \%$. 
doméstico femenino que, en cifras relativas, ha pasado de representar un $9,8 \%$ de todo el trabajo asalariado femenino en 2007 a un $8,6 \%$ cinco años más tarde ${ }^{3}$.

\section{Determinantes socioeconómicos del crecimiento del sector doméstico}

Desde una perspectiva global, la actividad de los mercados ha impulsado el crecimiento de empresas multinacionales que requieren de mano de obra cualificada, altos ejecutivos, profesionales y técnicos que se mueven de unos lugares a otros y permanecen fuera de casa durante inciertos periodos de tiempo. Como ha puesto de manifiesto Sassen (2010), la movilidad geográfica del personal cualificado y la creciente e intensa dedicación al empleo generan una nueva demanda de trabajadores para cubrir las necesidades domésticas, lo que da paso al surgimiento de empleos auxiliares mal remunerados.

\subsection{De cómo las desigualdades socioeconómicas intervienen en la genera- ción de empleo doméstico}

A la hora de analizar los factores económicos que contribuyen a la reconstrucción del sector doméstico en España destacamos en este apartado, por un lado, las desigualdades estructurales existentes en relación con la distribución de la renta y los ingresos y, por otro lado, la organización del mercado de trabajo y las características del modelo productivo. Con respecto a las desigualdades económicas se examina cómo afectan a la formación y extensión del mercado laboral doméstico ${ }^{4}$. En este sentido, la parca labor redistributiva del Estado en materia de organización social del cuidado, con bajas prestaciones y escasos servicios públicos, deja paso a la iniciativa privada, donde las fuerzas del mercado actúan según rentas y recursos de la población. En relación con el mercado laboral doméstico, la disparidad de ingresos y salarios, entre quienes ofertan y demandan trabajo, constituye una condición estructural para su desarrollo. Sin embargo, esa condición queda neutralizada cuando la aportación de las familias o de los poderes públicos sustituyen las carencias económicas de los demandantes y posibilitan el acceso al servicio doméstico.

${ }^{3}$ Una evolución que vendría a mostrar que la pérdida de empleo femenino en este sector de actividad se está compensado con la entrada paulatina de varones en el mismo. De hecho en esos cinco años el empleo masculino se ha incrementado en 6.000 trabajadores.

${ }^{4}$ Las desigualdades de ingresos se consideran como punto de partida, es decir, como condición que limita la capacidad de los actores para poder elegir entre opciones diversas. De acuerdo con Sen (2004:40), estudiar la desigualdad desde el punto de vista de los ingresos, únicamente, no es acertado para conocer la situación de bienestar y, en este caso, como se verá más adelante, la satisfacción de la demanda de cuidados no depende sólo de la capacidad económica sino que tiene también otros condicionantes. 
La estratificación de la sociedad española remite a viejas desigualdades de índole económica observadas tanto en base a la distribución de ingresos como en la capacidad de gasto. Los estudios en esta materia reflejan que el fenómeno de la desigualdad socioeconómica en España no es coyuntural, aunque se haya agudizado en los últimos tiempos, sino que se arrastra desde largas décadas atrás. Como distintos autores han mostrado, los periodos de crecimiento económico no conllevan necesariamente una mejora en el bienestar del conjunto de la población (Salido, 2008:220) puesto que, como ha ocurrido en los años previos a la actual recesión económica, la riqueza producida no se ha distribuido de manera igualitaria sino que se ha acumulado en favor de los más acaudalados (Stiglitz, 2009:8).

A comienzos de la segunda década del siglo XXI España sigue siendo uno de los países desarrollados con mayores desigualdades. En relación con la Unión Europea de los 27 (UE-27) sólo se ve superado por Portugal, Bulgaria y Letonia; el índice de Gini ${ }^{6}$ muestra, para 2011, un valor de 34 cuando la media de la EU-27 está en 30,7 y en Noruega, el país más igualitario, alcanza un 22,9. La mala posición española en los indicadores de desigualdad se corrobora cuando se observa la ratio de los ingresos de los más ricos en relación con los más pobres; los ingresos disponibles del quintil superior con respecto a los ingresos del quintil inferior (los que menos tienen) es 6,8 en 2011; lo que significa que el $20 \%$ de la población más rica acumula siete veces más ingresos que el $20 \%$ más pobre. Este dato coloca a España como el país más desigual de toda la UE-27, cuya media alcanza una ratio de 5,1.

Con carácter general, cuanto mayor es la diferencia de ingresos entre ricos y pobres, mayor es el potencial para que surjan empleos auxiliares de baja remuneración y bajo salario. Como hemos señalado en otro lugar, allí donde las desigualdades económicas son mayores la proporción de ocupados en el sector doméstico es más elevada (García Sainz, 2011:47-48), lo que se comprueba al observar los datos sobre desigualdad y empleo doméstico en distintos países de la Unión Europea. De hecho, entre las razones por las que el trabajo doméstico remunerado tiene tan poca incidencia en los países nórdicos figura la distribución más igualitaria de la renta, lo que deja un campo más reducido para el surgimiento de empleos de baja calidad, tal y como muestra Liebig (2009:47) para el caso de Noruega.

${ }^{5}$ Stiglitz ha señalado que las políticas monetarias de las últimas décadas han contribuido a que el dinero fluya hacia los más ricos, lo que ha provocado una mayor brecha en las desigualdades socioeconómicas. Aunque este autor centra su análisis de la disparidad en los EE.UU. (Stiglitz, 2012:48-49), sus conclusiones pueden extrapolarse al caso español.

${ }^{6}$ El índice de Gini mide la desigualdad existente en los países según la distribución de los ingresos (o del consumo) entre los individuos o los hogares. El coeficiente expresa una relación que va desde una distribución de perfecta igualdad $(=0)$ a una de completa desigualdad (=100); cuando más elevado es el coeficiente más desigual es el país. 
En este sentido, Milkman, Reese y Roth (1998:487) sostienen que el crecimiento del empleo doméstico depende más de la desigualdad de clase que de otros factores como la inmigración o la ocupación de las madres. En los países nórdicos, donde hay mayor equilibrio en el reparto del trabajo por género, el sector público tiene más peso y el Estado de bienestar está más consolidado, la externalización del servicio doméstico tiende a compartirse entre la iniciativa estatal y la prestación de las familias; incluso, las personas ocupadas en trabajos de cuidado cuentan con niveles salariales y condiciones laborales más favorables, que en otros lugares con mayor desigualdad, parecidos a los de otros empleados de similares características (Razavi y Saab, 2010:458).

Para el caso de España, la Encuesta de estructura salarial (INE, 2010), muestra que el salario medio ascendía, en el citado año, a 22.790,20 € anuales. Sin embargo, mientras el diez por ciento de los trabajadores con menores salarios ganaron un media de 8.643,66 €, el diez por ciento de los que más ingresaron declararon un salario medio de 40.811,42 €, es decir, casi cinco veces más. Esta ratio se corresponde con la cifra que expresa la distancia de ingresos que hace posible que los grupos con mejor situación socioeconómica contraten trabajos auxiliares con salarios reducidos. Como señala Recio (1999:133), estamos posiblemente ante un proceso que se autorrefuerza, ya que la polarización de los ingresos conduce a la demanda de trabajos de bajo salario y, a su vez, la emergencia de trabajos mal remunerados como el doméstico, reproduce la estratificación social.

La observación de la cuantía de los salarios por grupos sociales y ocupaciones en base a los datos de la citada Encuesta, refleja, al menos, dos aspectos de interés; por un lado, la diferencia que se produce entre distintas ocupaciones. En este sentido, los salarios más elevados corresponden al grupo ocupacional de directores y gerentes, cuyos ingresos superan en un 148,4\% los salarios medios y, en el lado opuesto se hallan las retribuciones de quienes desempeñan "ocupaciones elementales", en el que se incluyen empleados domésticos ${ }^{7}$, otro personal de limpieza, basureros, vendedores ambulantes y peones agrarios, de la construcción, de la industria y de los transportes, cuyas retribuciones se encuentran un $39,3 \%$ por debajo del salario medio. Por otro lado, se hallan las diferencias salariales por

\footnotetext{
${ }^{7}$ Lamentablemente no disponemos de la cuantía del salario del grupo de empleados domésticos ya que la Encuesta de estructura salarial (con criterios de EUROSTAT), no recoge información de empleados que desempeñan su actividad en unidades de menos de 10 trabajadores. Sin embargo, la ausencia de datos de la citada Encuesta se ve compensada con la precisión con la que el Ministerio de Empleo estipula mediante Real Decreto el salario mínimo interprofesional para cada año. El RD 1717/2012 que fija la cuantía del salario mínimo para 2013 lo hace con carácter general y solamente desciende al detalle en los casos de trabajadores eventuales, temporeros y empleados de hogar. Para estos últimos establece un sueldo mínimo de 5,05€ por hora efectivamente trabajada (R.D., 2012), cuando el salario medio por hora trabajada se sitúa en 14,52 € para todas las ocupaciones (INE, 2010).
} 
género. Así, la brecha de género, medida en la ganancia por hora trabajada, entre hombres y mujeres se sitúa en un $15,3 \%$ con carácter general, que se ve incrementada en este sector altamente feminizado, en el que la segregación salarial descansa, además de en el género, en el tipo de ocupación y en la etnia.

Con todo, en el ámbito económico, las desigualdades de ingresos y la polarización de los salarios no son elementos suficientes para explicar el crecimiento del sector doméstico en España en la pasada década. Como señalamos al comienzo, muchos hogares que contratan cuidadoras o empleados de hogar están regentados por personas mayores, a menudo de frágil salud o dependientes y con baja capacidad adquisitiva, cuyos ingresos dependen de pensiones de viudedad o de jubilación de escasa cuantía. Desde la perspectiva tradicional de la teoría de clases podría argumentarse que este grupo de población se ha convertido en una nueva categoría empresarial y sus hogares en microempresas con capacidad de contratar personal y generar empleo. Sin embargo, las características de la actividad doméstica remunerada y las de la relación laboral que la sustentan no son las de otros empleos asalariados. Por el lado de quienes contratan, la figura del empleador (demandante de cuidados) es más bien difusa ya que, en ocasiones, quien contrata y recibe el servicio no dispone de capacidad ni de recursos para pactar directamente las condiciones de la relación. Con frecuencia los grupos sociales que más demandan trabajo de cuidados (personas mayores, niños, enfermos) cuentan con economías poco solventes; es por ello que, en muchos casos, la opción de contratar servicio doméstico no es una decisión emprendedora al uso sino el resultado de una estrategia familiar. El apoyo económico, (generalmente transferencias económicas que pasan de hijos/as a padres/madres) y los bajos salarios del sector posibilitan el acceso al servicio doméstico a personas que son dependientes, y lo son, no sólo por motivos de edad o de salud sino también por carencia de recursos económicos. Por el lado de las personas contratadas, una gran mayoría son inmigrantes que trabajan por horas o que residen en el mismo domicilio en el que trabajan y que, muchas veces, se encuentran en una situación económica y administrativa vulnerable, porque carecen de la documentación que les facilita una residencia regularizada y estable en el país. De esta compleja relación entre demandantes del servicio y quienes lo prestan, como cuidadoras, no se deriva enfrentamiento entre individuos movidos por intereses antagónicos, sino una relación ambivalente, que con frecuencia resulta ser de mutuo apoyo entre sujetos socialmente frágiles que dependen de terceros para conservar su situación.

Aunque ni la normativa laboral ni las políticas sociales lo contemplan, la regulación y tratamiento del servicio doméstico debería atender, al menos, a los dos tipos de empleo doméstico que se observan actualmente en este ámbito de trabajo; por un lado, el empleo del hogar tradicional, relacionado con la posición de clase y, más recientemente, con los profesionales de las ciudades globales, y, por otro lado, el nuevo empleo de cuidado doméstico, que surge con los cambios sociales de las 
últimas décadas y la necesidad de las familias trabajadoras de atender el cuidado de dependientes, para lo que contratan mano de obra inmigrante ${ }^{8}$. El tratamiento del servicio doméstico como un todo indiferenciado, sin distinguir entre modalidades de prestación, mantiene en la sombra la demanda social de cuidado y el déficit de cuidadores, además de ignorar los contextos y la diversidad en los que dicho trabajo se realiza. Significa, en la práctica, que una parte de este trabajo, especialmente el relacionado con los cuidados, no es reconocido como tal y continúa desatendido por las políticas públicas (Carrasco et al., 2011) además de por las estadísticas laborales y por los indicadores de actividad económica.

\subsection{Del modelo productivo, los mercados de trabajo y el empleo doméstico}

La organización social del cuidado no es ajena a las políticas económicas de las últimas tres décadas que, siguiendo la pauta del modelo liberal imperante en los países desarrollados, se han orientado a la liberalización y la desregulación de los mercados para estimular la actividad económica. Este modelo, que ha primado el enriquecimiento fácil y la maximización de los beneficios, se asienta sobre la explotación desmesurada de los recursos y la privatización del patrimonio y los servicios públicos. Las medidas puestas en práctica en este sentido han contribuido a debilitar los Estados de bienestar, lo que repercute especialmente en los sectores socialmente más vulnerables, como los mayores y/o dependientes, que ven aminorados los servicios destinados para ellos, como la ayuda a domicilio o la reducción de las prestaciones que reciben quienes les cuidan ${ }^{9}$. Como resultado de la escasez y el deterioro de la atención pública en este ámbito la responsabilidad de cuidar a los dependientes rebota del sector público al privado, para que sigan siendo los hogares quienes les atiendan. Dicho en otras palabras, este giro refuerza del familiarismo, en tanto que son, una vez más, los miembros de la familia, mayoritariamente las mujeres, quienes tienen que paliar la debilidad redistributiva del Estado y sustituir sus carencias sociales.

Junto a las características del modelo productivo es preciso contemplar la organización del mercado de trabajo como un factor fundamental para comprender la extensión del empleo doméstico en España, puesto que, dicho mercado "segmenta y estratifica el empleo y lo hace produciendo distintos niveles de calidad

${ }^{8}$ El bajo coste laboral asociado al empleo de trabajadores inmigrantes ha hecho asequible el servicio doméstico a personas con ingresos medios; aunque, obviamente, las clases acomodadas también han obtenido beneficio del bajo coste de la mano de obra de origen extranjero.

${ }^{9}$ Desde 2012 el Gobierno Rajoy ha reducido drásticamente el presupuesto destinado a los servicios incluidos en el Sistema de Atención a la Dependencia. Entre otros recortes, que afectan por ejemplo a los servicios sociales, la Administración ha dejado de hacerse cargo de la cotización a la Seguridad Social de los cuidadores no profesionales que atienden a dependientes en el hogar, además de reducir la cuantía de su remuneración. 
y decencia" (Prieto, 2009:130-131). En este sentido, distintos autores han analizado la relación entre la segmentación del mercado de trabajo y el crecimiento de empleos irregulares, de baja cualificación y mal remunerados (Colectivo IOÉ, 1990; Noya, 2004; Cachón, 2009) como el doméstico.

La mayor parte de los estudios realizados en España sobre servicio doméstico desde la perspectiva de las relaciones laborales lo vinculan a la economía sumergida y al empleo informal (Colectivo IOÉ, 1990; Banyuls et ál. 2002/2003; Centro de Estudios Tomillo, 2005; Pla Julián, 2008, Pla-Julián y Giménez-Moreno, 2012) y coinciden en destacar la precariedad y la irregularidad que lo caracterizan, atendiendo, entre otros aspectos, a los bajos salarios, las jornadas laborales excesivas, así como la escasa cobertura legal y protección social de las personas que lo desempeñan ${ }^{10}$. Los estudios sobre la calidad del empleo (Comisión Europea, 2003; Prieto, 2009) asocian estas variables de incertidumbre e inseguridad, falta de protección, bajo salario y jornadas excesivas (que dificultan la conciliación entre vida laboral y personal), con los empleos de baja calidad. La comparación de estas características a escala europea refleja que la situación del empleo en España se encuentra entre las más desfavorables (Ghai, 2003:151).

A escala internacional, como distintos estudios han puesto de manifiesto, el servicio doméstico es uno de los sectores de actividad con las condiciones laborales más precarias (Anderson, 2000; Salazar Parreñas, 2001; Zimmerman, et ál., 2006; OIT, 2013) y con los salarios más bajos en prácticamente todos los lugares del mundo. Aunque existen grandes variaciones en las remuneraciones percibidas en el sector doméstico entre unos países y otros, los datos globales aportados por la OIT (2013) muestran que la remuneración de estos trabajadores se sitúa en torno al $40 \%$ de los salarios medios de la población trabajadora en su conjunto.

Razavi y Saab (2010:454-455) han analizado las razones de los bajos salarios que perciben las personas dedicadas al trabajo de cuidados y destacan, entre ellas: su baja productividad, pues la alta dedicación de tiempo que requiere impide que sea competitivo; b) las normas sociales, que vinculan el cuidado con una actividad altruista, que se hace por amor, donde se interpreta que el salario no es prioritario; c) la segregación por género, dado que socialmente los trabajos asistenciales se asignan a las mujeres, y d) la escasa capacidad económica de los grupos que más demandan el trabajo de cuidado, los niños, los mayores y los enfermos. A menudo se afirma que se trata de un trabajo improductivo y poco cualificado, cuando su realización es esencial y requiere un conjunto de saberes, habilidades y

${ }^{10}$ Cerca de la mitad de esta población asalariada del sector trabaja al margen de normativas y condiciones legales. En 2012 de las 660.000 personas que la Encuesta de población activa (INE) recoge como asalariadas sólo 350.000 figuran como afiliadas en el Sistema especial de empleados de hogar de la Seguridad Social (Ministerio de Empleo y Seguridad Social). 
experiencia ${ }^{11}$. Sin embargo, posiblemente la principal razón por la que el sector doméstico es un ámbito de baja remuneración no sea tanto por las características del trabajo que se han citado, ni por las cualificaciones de quienes lo realizan, sino por la funcionalidad que tiene para la estructura laboral mantenerlo en dichas condiciones, es decir, como ámbito segregado (mal pagado) en la pirámide laboral (segmentada) que fortalece el orden social (estratificado).

Tras la aprobación del Convenio 189 y la Recomendación sobre Trabajo decente para las trabajadoras y los trabajadores domésticos, en 2011, la OIT insta a los gobiernos a tomar medidas para convertir esta actividad en un trabajo decente. Para la OIT, un trabajo decente es aquel libremente elegido, al que se le aplican los derechos fundamentales que se reconocen a todo trabajo, que proporciona unos ingresos que permiten satisfacer las necesidades personales y familiares y que contiene una adecuada protección social (Ghai, 2003; OIT, 2007). Esta definición de trabajo decente (OIT) difiere ligeramente de la noción de trabajo de calidad, acuñada por la Comisión Europea. Mientras la primera alude a un trabajo en condiciones de libertad, equidad, seguridad y dignidad humana, la segunda se apoya en un conjunto heterogéneo de dimensiones, como calidad intrínseca del trabajo, cualificación, flexibilidad y seguridad, diálogo social, diversidad y no discriminación, entre otras (en Prieto, 2009:28-29 y 41). En tanto que la OIT apuesta con claridad por la defensa, seguridad y protección del sujeto trabajador, la Comisión Europea relaciona el trabajo de calidad con la eficacia, la productividad y la rentabilidad económica (Prieto, 2009:42). Esta distinción se resulta especialmente útil a la hora de abordar los límites del reconocimiento del trabajo doméstico y de cuidados, dado que mientras puede aspirar a tener el estatus de trabajo decente resulta más difícil que pueda adquirir la condición de empleo de calidad en los términos que la Comisión Europea lo describe. Es decir, el trabajo doméstico y, especialmente el que se destina al cuidado de las personas, no busca la eficiencia, ni la productividad, tampoco está ligado a la obtención de beneficios económicos para los empleadores; por lo tanto, no podrá ser considerado como un empleo rentable, en sentido estricto, aunque sea esencial para el bienestar y el desarrollo social.

${ }^{11}$ Como se verá más adelante la atribuida baja cualificación del trabajo doméstico y de cuidados es, cuando menos cuestionable, ya que requiere de formación, destrezas y capacidades similares a las de otros empleos, cuando no, conocimientos de enfermería, medicina y otros campos especializados (Standing, 2003:42). Budig y Misra (2010), por su parte, afirman que el trabajo de cuidados no está peor remunerado porque sea menos cualificado sino porque está feminizado. 


\section{Normativa de extranjería y legislación laboral del servicio doméstico}

El carácter informal que caracteriza al empleo doméstico está estrechamente vinculado a la normativa laboral que lo regula así como a otra legislación aplicable a buena parte de las personas que lo desempeñan: las inmigrantes. Para el caso de España, puede afirmarse que la combinación de las sucesivas reformas de las leyes de extranjería con las leyes laborales dictadas específicamente para el trabajo doméstico conduce a que este sector de ocupación se mantenga parcialmente oculto y a que quienes desempeñan esta actividad permanezcan en condiciones de irregularidad ("sin papeles") y de informalidad laboral (sin contrato).

\subsection{De cómo la legislación en materia de extranjería condiciona la movilidad social y ocupacional de las inmigrantes}

La legislación española en materia de extranjería distingue entre dos vías de entrada de mano de obra extranjera: ordinarias y extraordinarias ${ }^{12}$. Mientras las primeras se centran en la contratación en origen, las extraordinarias se asocian a procesos de regularización en destino. Una vez en el país, el proceso de regularización requiere tener en cuenta el sistema de permisos de trabajo, puesto en marcha en 1996, que contempla la concesión de autorizaciones para trabajos de «temporada», o autorizaciones «temporales». La primera autorización que se concede para trabajar es para un año y contiene generalmente limitaciones sectoriales y geográficas. Trascurrido el año, el permiso se renueva dos veces cada dos años, siendo válido para trabajar en cualquier actividad y en todo el territorio español. Tras cinco años de autorizaciones temporales renovables, se otorga una autorización de residencia «permanente» que también conlleva la autorización para trabajar. El paso de una etapa a otra requiere el cumplimiento de determinados requisitos como: acreditar la continuidad en la relación laboral; tener un nuevo contrato o una oferta de empleo; haber trabajado al menos tres meses por año y en el caso de que se perdiera el trabajo, por causas ajenas a la voluntad de la trabajadora, buscar activamente empleo y en el momento de la solicitud tener un contrato en vigor; y ser beneficiario de la prestación contributiva por desempleo o de una prestación económica asistencial de carácter público.

Esta normativa tiene efectos directos sobre los itinerarios sociales y laborales de las y los inmigrantes. Como resultado de su aplicación muchas de estas personas se ven arrojadas a las posiciones sociales más bajas y a los sectores de ocupación menos deseables, dado que son autorizadas a trabajar en aquellas ramas o sectores

${ }^{12}$ LO 4/2000, de 11 de enero, de derechos y libertades de los extranjeros en España y su integración social, reformada mediante LO 8/2000, de 22 de diciembre, y LO 14/2003 de 20 de noviembre, así como su Reglamento de ejecución (RD 2393/2004, de 30 de diciembre). La ley actualmente en vigor, la LO 2/2009, se ha presentado, en realidad, como una reforma más de la LO 4/2000. 
de actividad que resultan de difícil cobertura por parte de la población autóctona. En unos casos, que sea una ocupación de difícil cobertura depende de la formulación con carácter previo de un juicio que dirima su compatibilidad con la situación nacional de empleo, mientras que en otros está condicionado a una previsión de los empleos que pueden cubrirse con mano de obra extranjera, por provincias, sectores de actividad y para períodos de tiempo determinados. Cualquiera que sea la modalidad de contratación, los efectos que se derivan son los mismos. Por una parte, se constata que ciertas ramas de actividad terminan quedando reservadas a los extranjeros, de manera que aquéllos que aspiren a regularizar su situación (y mantenerla una vez alcanzada) deberán aceptar este tipo empleos, independientemente de sus capacidades y experiencia laboral. Por otra, ocurre que aquellos sectores que resultan compatibles con la situación nacional de empleo, o que se cubren con el denominado contingente, suelen ser los menos apetecibles o deseados por la población autóctona, fundamentalmente debido a su alto grado de precariedad ${ }^{13}$; el servicio doméstico es uno de ellos.

\subsection{De cómo la regulación del trabajo doméstico en España institucionaliza la inestabilidad de las trabajadoras}

Con respecto a la regulación del trabajo doméstico en España, en fechas recientes ha tenido lugar la integración de lo que hasta entonces había sido un régimen especial (el Régimen Especial de Empleados de Hogar) en el Régimen General de la Seguridad Social ${ }^{14}$. Desde 1985 los aspectos laborales de la relación

${ }^{13}$ Los permisos temporales de trabajo tienen en las personas inmigrantes el efecto de "estrella apagada": "aunque se apague la luz, aunque desaparezcan las restricciones (formales), este marco institucional discriminatorio que conduce a limitar la actividad en el primer año a un sector y a un ámbito geográfico concreto, continúa produciendo efectos, sigue teniendo consecuencias durante mucho tiempo" (Cachón, 2009:181). Respecto a las ramas o sectores de actividad que se cubren con el contingente, se advierte que "quedan marcadas zonas laborales y a la vez marcan el camino que deben seguir quienes se incorporan al mercado de trabajo en España, en su mayoría sin tener necesariamente en cuenta sus capacidades y experiencia laboral porque lo que prima en el juego de oferta y demanda es esta última y sus necesidades. Y al hacer entrar por esas vías, al final consolida muchas posiciones en esos sectores» (Cachón, 2009:187).

${ }^{14}$ La Disposición Adicional Trigésimo Novena de la Ley 27/2011, de 1 de agosto, sobre actualización, adecuación y modernización del sistema de la Seguridad Social, ha procedido, con efectos desde el 1 de enero de 2012, a integrar el Régimen Especial de Empleados de Hogar dentro del Régimen General, mediante la creación del Sistema Especial para Empleados de Hogar. En este contexto, se arbitran medidas diversas de desarrollo, como el Real Decreto 1620/2011, de 14 de noviembre, por el que se regula la relación laboral de carácter especial del servicio del hogar familiar. Recientemente, el Consejo de Ministros aprobó el Real Decreto-ley 29/2012, de 28 de diciembre, de mejora de gestión y protección 
habían estado regulados en un Decreto que caracterizaba el trabajo prestado en el hogar familiar como especial ${ }^{15}$. Eso ha llevado a que, frente a la normativa común, se arbitrasen medidas específicas con relación a sus condiciones de desempeño, lo que ha generado cierta polémica entre los colectivos afectados. En la tabla que se inserta a continuación se resumen los puntos principales de la reforma aprobada recientemente en relación con la anterior regulación.

\section{Tabla 1}

\section{La regulación del servicio doméstico en España}

Comparación entre la regulación antigua y la regulación actual (incluyendo las reformas acordadas mediante RDL 29/2012 de 28 de diciembre)

\begin{tabular}{|l|l|}
\hline \multicolumn{1}{|c|}{ Regulación antigua } & \multicolumn{1}{c|}{ Regulación actual } \\
\hline $\begin{array}{l}\text { No existe obligación de formalizar el } \\
\text { contrato por escrito. }\end{array}$ & $\begin{array}{l}\text { Existe obligación de formalizar el contrato } \\
\text { por escrito. }\end{array}$ \\
\hline $\begin{array}{l}\text { Se presume que la duración del } \\
\text { contrato es de un año. }\end{array}$ & $\begin{array}{l}\text { Se aplicarán las normas generales sobre } \\
\text { duración del contrato. }\end{array}$ \\
\hline $\begin{array}{l}\text { La remuneración en especie no podrá } \\
\text { superar el 45\%. }\end{array}$ & $\begin{array}{l}\text { Se garantiza como mínimo el pago en } \\
\text { metálico del Salario Mínimo Interprofesio- } \\
\text { nal (SMI), en cómputo anual. La remunera- } \\
\text { ción en especie no podrá superar el 30\%. }\end{array}$ \\
\hline $\begin{array}{l}\text { Derecho a 15 días de salario en } \\
\text { concepto de paga extraordinaria. }\end{array}$ & $\begin{array}{l}\text { Derecho a dos pagas extraordinarias al año } \\
\text { cuya cuantía no podrá ser inferior al SMI } \\
\text { mensual. }\end{array}$ \\
\hline $\begin{array}{l}\text { Diez horas de descanso entre jorna- } \\
\text { das. }\end{array}$ & Doce horas de descanso entre jornadas. \\
\hline $\begin{array}{l}\text { Cuando la actividad se realice en } \\
\text { régimen de pernocta, se admitirá un } \\
\text { mínimo de ocho horas. }\end{array}$ & $\begin{array}{l}\text { Cuando la actividad se realice en régimen } \\
\text { de pernocta, se admitirá un mínimo de diez } \\
\text { horas, y deberá compensarse la diferencia } \\
\text { hasta las doce horas en períodos de hasta } \\
\text { cuatro semanas. }\end{array}$ \\
\hline $\begin{array}{l}\text { No se requiere comunicación expresa } \\
\text { por el empleador del desistimiento, y } \\
\text { la indemnización será de diez días de } \\
\text { salario por año de servicio. }\end{array}$ & $\begin{array}{l}\text { Se requiere comunicación expresa por el } \\
\text { empleador del desistimiento. La indemni- } \\
\text { zación será de doce días de salario por año } \\
\text { de servicio. }\end{array}$ \\
\hline
\end{tabular}

social en el Sistema Especial para Empleados de Hogar y otras medidas de carácter económico y social.

${ }^{15} \mathrm{RD} 1424 / 1985$, de 1 de agosto. 


\begin{tabular}{|l|l|}
\hline $\begin{array}{l}\text { La cuota es única. Se excluye la } \\
\text { contingencia por desempleo, y la } \\
\text { contingencia por incapacidad tempo- } \\
\text { ral sigue un régimen propio. }\end{array}$ & $\begin{array}{l}\text { Se contribuirá a la Seguridad Social en } \\
\text { función de las horas efectivamente trabaja- } \\
\text { das (la última reforma ha simplificado los } \\
\text { tramos de cotización). Se excluye la con- } \\
\text { tingencia por desempleo. Con independen- } \\
\text { cia de las horas trabajadas y del número de } \\
\text { empleadores para los que el trabajador } \\
\text { preste sus servicios, la obligación de cotizar } \\
\text { corresponde exclusivamente a los emplea- } \\
\text { dores, con una excepción: si las horas } \\
\text { trabajadas no excedieran de sesenta al mes, } \\
\text { entonces, el empleador podrá delegar, } \\
\text { siempre que medie pacto escrito, en el } \\
\text { trabajador la obligación de ingresar la } \\
\text { cuota. }\end{array}$ \\
\hline $\begin{array}{l}\text { Las tareas domésticas prestadas a personas } \\
\text { jurídicas darán lugar a la inclusión del } \\
\text { trabajador en el régimen general como } \\
\text { trabajador por cuenta ajena. }\end{array}$ \\
\hline
\end{tabular}

Fuente: Elaboración propia.

Por lo que respecta a la valoración que ha merecido la nueva normativa, las posturas son diversas; al año de su puesta en marcha, el Ministerio de Empleo ha cuantificado la caída de la cotización en 63 millones de euros por un descenso generalizado en las bases del $30 \%$, los sindicatos se han referido al proceso de integración como «un éxito evidente» y las asociaciones mantienen una posición crítica. Con todo, si bien resulta cierto que introduce mayor seguridad jurídica para las partes (la nueva regulación del desistimiento es un ejemplo claro ${ }^{16}$ ), no resuelve otros problemas. Por ejemplo, sigue sin contemplarse la protección por desempleo, lo que constituye una excepción a los derechos reconocidos para el conjunto de los trabajadores $\mathrm{y}$, por otro lado, la nueva regulación no está produciendo los efectos deseados, en el sentido de sacar a la luz buena parte de la economía sumergida existente en este sector de actividad. De hecho, de las casi 700.000 personas trabajando en el servicio doméstico, desde enero hasta el mes de agosto de 2012 solo se habrían producido alrededor de 80.000 nuevas altas. 80.000 es el saldo que resulta al descontar de las 158.035 nuevas afiliaciones 74.524 que figuraban de alta en el antiguo régimen y que no han seguido en el nuevo sistema. Entre las razones que se han esgrimido para explicar que no se haya conseguido reducir la economía sumergida se invocan la complejidad burocrática que ha supuesto la nueva

${ }^{16}$ Tampoco en este punto existe unanimidad al respecto. Las trabajadoras domésticas exigen en realidad su desaparición, al entender que en la práctica se convierte en una vía subrepticia para ocultar una forma de despido que resulta improcedente. 
regulación, así como el incremento del coste en las cotizaciones que supone para los hogares. Además, la última reforma ha supuesto una subida importante del coste en las cotizaciones, especialmente en los primeros tramos, lo que hace pensar que aumentará aún más la economía sumergida en este sector. En otro orden de cosas, la desaparición de la figura del trabajador discontinuo, que laboraba para varios empleadores y que cotizaba por cuenta propia, plantea el problema de que no se alcance la cotización mínima exigida ${ }^{17} \mathrm{o}$, en el caso de las personas inmigrantes, que éstas caigan en una situación de irregularidad sobrevenida (al no poder instar ellas mismas su alta en la Seguridad Social). Si bien es cierto que este punto ha sido revisado en la última reforma, la solución adoptada dista de ser satisfactoria. El hecho de que sea ahora el personal discontinuo el que pueda hacerse cargo de la obligación de cotizar por cuenta del empleador supone de facto transferir a aquél responsabilidades que realmente corresponden a éste. Del mismo modo, sigue sin prestarse atención a las inmigrantes que, aún en el supuesto de que pudieran asumir dicha obligación, dado que solo pueden acogerse a esta medida quienes no excedan de las sesenta horas mensuales trabajadas para un mismo empleador, presumiblemente no lograrán completar los períodos de cotización exigidos para poder renovar su autorización de trabajo. Por lo demás, desde diferentes colectivos sociales, se está denunciando que, desde la reforma de 2011, bastantes trabajadoras domésticas están perdiendo su empleo, o bien que se ven obligadas a aceptar rebajas en sus salarios (al repercutir sobre éstos las nuevas obligaciones).

En el plano internacional, el Convenio recientemente aprobado por la OIT, que España aún no ha ratificado ${ }^{18}$, se presenta como un consenso de mínimos, mientras que las propuestas de más alcance quedan planteadas en términos de meras recomendaciones, y por tanto, sin carácter vinculante para los Estados firmantes. En la siguiente tabla se reproducen los contenidos principales de dichas recomendaciones.

${ }^{17}$ A las trabajadoras se les reconocía la posibilidad de firmar un convenio con la Seguridad Social para completar la cotización; sin embargo, apenas se les ha informado de ello.

${ }^{18}$ Hasta la fecha, solo ha sido ratificado formalmente por cuatro países: Uruguay, Filipinas, Mauricio e Italia. 
Tabla 2

Recomendaciones al Convenio sobre el Trabajo Decente para las Trabajadoras y los Trabajadores Domésticos

\begin{tabular}{|c|}
\hline Contenidos principales \\
\hline Suprimir las restricciones y obstáculos al ejercicio del derecho de afiliación. \\
\hline $\begin{array}{l}\text { Respeto a los principios de confidencialidad y privacidad en el sistema de reconoci- } \\
\text { mientos médicos (entre otros aspectos, carácter voluntario, no obligatorio de las } \\
\text { pruebas de embarazo y de detección del VIH). }\end{array}$ \\
\hline Articulación de mecanismos de denuncia de casos de abuso, acoso y violencia. \\
\hline $\begin{array}{l}\text { Adopción de programas para la reubicación y readaptación de las y los trabajadores } \\
\text { domésticos víctimas de abuso, acoso y violencia. }\end{array}$ \\
\hline Establecimiento de un contrato de trabajo tipo para el trabajo doméstico. \\
\hline $\begin{array}{l}\text { Reglamentación del tiempo de presencia (número máximo de horas, período de } \\
\text { descanso compensatorio, remuneración). }\end{array}$ \\
\hline $\begin{array}{l}\text { Reglamentación del descanso semanal (entre otros aspectos, respeto a las necesida- } \\
\text { des culturales, sociales y religiosas de los trabajadores domésticos). }\end{array}$ \\
\hline $\begin{array}{l}\text { Reglamentación del pago en especie (entre otros aspectos, establecimiento de un } \\
\text { tope máximo, cuyo cálculo deberá realizarse con arreglo a criterios objetivos, limi- } \\
\text { tado al alojamiento y la manutención). }\end{array}$ \\
\hline $\begin{array}{l}\text { Adopción de medidas para la protección de los créditos laborales en caso de insol- } \\
\text { vencia o fallecimiento del empleador. }\end{array}$ \\
\hline Reglamentación de las condiciones de alojamiento y alimentación. \\
\hline Protección frente a peligros y riesgos relacionados con el trabajo. \\
\hline Prevención del trabajo forzoso y de la trata de personas. \\
\hline $\begin{array}{l}\text { Igualdad de trato con respecto a la seguridad social, acceso a los derechos de seguri- } \\
\text { dad social y al mantenimiento o transferibilidad de tales derechos. }\end{array}$ \\
\hline $\begin{array}{l}\text { Reglamentación de medidas adicionales de protección del trabajador o trabajadora } \\
\text { migrante (entre otros aspectos, de fondos de asistencia jurídica, servicios sociales y } \\
\text { servicios consulares especializados, articulación del derecho a ser repatriados). }\end{array}$ \\
\hline Autorización de inspecciones de trabajo. \\
\hline Conciliación de la vida familiar y laboral. \\
\hline Refuerzo de la capacidad de las oficinas nacionales de estadística. \\
\hline Seguimiento de las actividades de las agencias privadas de colocación. \\
\hline $\begin{array}{l}\text { Principio de cooperación entre los Estados miembros con el propósito de mejorar la } \\
\text { protección de los trabajadores del servicio doméstico. }\end{array}$ \\
\hline
\end{tabular}

Fuente: Elaboración propia. 
En suma, frente a la tendencia general que se observa en la legislación laboral a proteger a los trabajadores, la regulación actual del trabajo doméstico resulta una excepción clara. La precariedad e inestabilidad, lejos de desaparecer, se formalizan ${ }^{19}$.

\section{La intermediación de los programas de empleo en el servicio doméstico}

Además de por los aspectos citados, desigualdades económicas, segmentación laboral y una normativa laxa, el sector doméstico se construye en base a factores institucionales que, en este caso, se concretan en la actividad mediadora de los "programas de empleo". Bajo esta rúbrica se incluye un conjunto de actuaciones diversas relacionadas con el empleo (que comprenderían fundamentalmente la orientación e intermediación laborales), que son planificadas y realizadas preferentemente por asociaciones y otras entidades sin ánimo de lucro, financiadas con fondos públicos y cuyos destinatarios son primordialmente colectivos demandantes de empleo con dificultades especiales de inserción. En lo que aquí interesa, conviene insistir en que la valoración última que se haga de estos programas está asociada con el problema de la oportunidad y los límites de las, así denominadas, políticas selectivas de empleo (Gómez Millán, 2011). En el caso que nos ocupa, cuyos resultados se analizan en las páginas siguientes, nuestra tesis es que, tal y como aparecen articulados, exigirían una profunda reestructuración, pues lejos de combatir ciertos factores discriminatorios, vinculados al género y la nacionalidad, que limitan la participan de las inmigrantes en el mercado de trabajo, los ameritan.

Algunos estudios, como los de Martín Artiles et al., (2011), Cachón (2007), Solé et al., (2008) y Caparrós y Navarro (2010), muestran que las inmigrantes tienen menos posibilidades de realizar trayectorias laborales ascendentes y cuentan con salarios inferiores que sus homólogos varones. Además, perciben salarios menores que las autóctonas en oficios similares y sus trayectorias laborales son más retardadas. En la transición desde el mercado de trabajo en origen hasta su inserción en la sociedad de acogida, tienen mayores probabilidades que los hombres de

${ }^{19}$ El informe de la OIT (2013) cifra en 52 millones el número de empleados domésticos en el mundo, excluyendo a los menores de quince años, que no están comprendidos en las encuestas utilizadas para elaborar el informe y que un estudio fechado en 2008 cifra en casi 7,5 millones. El citado informe se refiere también a la feminización del sector (el $83 \%$ son mujeres), a la informalidad en la que trabajan (lo que hace suponer que la cifra real de empleados domésticos en el mundo se acerca a los cien millones), la vulnerabilidad (sólo el $10 \%$ están cubiertos por la legislación laboral en vigor para los demás trabajadores y más del $25 \%$ se encuentran completamente excluidos de cualquier legislación) y exposición a prácticas laborales abusivas, a situaciones de violencia, y a condiciones de vida indignas. 
descender en su primera inserción laboral. Circunstancias como el estado civil, el modo de convivencia o el número de hijos condicionan su movilidad ocupacional.

En este apartado analizamos cómo las acciones derivadas de las políticas selectivas de empleo, diseñadas por las instituciones públicas y llevadas a cabo a través de estos programas, afectan directamente la movilidad ocupacional de las inmigrantes. El trabajo empírico en el que se basa este análisis proviene de la explotación de datos obtenidos en la actividad de mediación laboral que se lleva a cabo a través de los programas de empleo. El periodo contemplado abarca desde 2005 a 2009, ambos años incluidos; un lustro que permite observar situaciones previas e insertas en la crisis económica, que afectan a la llegada de población inmigrante y a sus expectativas de empleo. La información seleccionada permite examinar las características ocupacionales (y personales) de quienes demandan empleo (usuarias principalmente) y los requisitos que presentan las ofertas. De esta manera se puede conocer el perfil, original y construido, de las demandantes que acuden a los programas de empleo en Madrid para iniciar un itinerario laboral. Las herramientas utilizadas para el análisis son, básicamente, cuestionarios y otros documentos (fichas) que se utilizan para la gestión de ofertas y demandas en los programas de empleo ${ }^{20}$. El análisis cuantitativo se ha basado en la explotación de los datos de las fuentes primarias correspondientes a ofertas y demandas y se ha complementado con la aplicación de diez entrevistas en profundidad a técnicos/as que trabajaban en programas de empleo, dedicados a la inserción laboral y al seguimiento del proceso de integración. El volumen de datos manejado asciende a cerca de 8.000 solicitudes de las que se han extraído 4.741 que corresponden a mujeres demandantes de empleo en el área de servicio doméstico. A esta base de datos hay que sumar 568 ofertas que, a lo largo del periodo, presentaron las familias para cubrir algún puesto de trabajo en los hogares. La observación de los perfiles ofrecidos por las demandantes permite comprobar que, en la mayoría de los casos, se construyen no tanto en base a sus saberes y experiencias sino a una adaptación de los mismos en función del mercado de trabajo al que se dirigen.

La información recogida, tanto por el tamaño de la muestra como por sus características, permite obtener datos valiosos en relación a cómo se articulan oferta y demanda en el mercado de trabajo doméstico y a cómo se comporta este sector a la hora de cubrir puestos de trabajo con mujeres inmigrantes, tanto en situación administrativa regular como irregular. El análisis en relación con este último campo, de trabajadoras en situación no regularizada, en una ocupación con alto volumen de empleo irregular, constituye una aportación significativa de este estudio, dada la escasez de información disponible en los registros oficiales para poder conocer cómo funciona el mercado laboral en este particular nicho de empleo doméstico en el que las inmigrantes en situación administrativa irregular tienen un peso significativo.

${ }^{20}$ Para un mayor detalle puede verse Valencia, 2011. 


\subsection{De cómo los programas de empleo conducen a sus usuarias hacia el sector doméstico}

La actividad de los programas de empleo se centra en articular la oferta y la demanda de trabajo doméstico, en un mercado laboral donde las mujeres inmigrantes son los sujetos destinatarios. En este sentido se destaca la labor de dinamización institucional, con la modelación de un perfil de las trabajadoras demandantes, la selección de requisitos con los que los hogares empleadores contribuyen a la empleabilidad de las demandantes y la propia labor de intermediación que se realiza en los programas específicos de inserción. En las páginas siguientes se recogen, por un lado, las características ocupacionales de las demandantes, en base a su narración y la forma en la que se ofrecen para ser contratadas en el sector doméstico ${ }^{21}$, así como sus expectativas de movilidad y, por otro lado, las particularidades de las ofertas según el esquema que trazan los hogares para construir un perfil, fijar los requisitos de empleo y establecer las condiciones laborales. El análisis de estas dos partes permite extraer algunas conclusiones sobre el papel que tienen los programas de empleo como formadores y dinamizadores de este sector de actividad.

\subsubsection{La gestación del perfil de las demandantes}

¿Cuál es el perfil de la población que utiliza el recurso de los programas de empleo para la buscar trabajo? Durante el periodo analizado (2005-2009), la procedencia de las usuarias era muy diversa, pues provenían de todas las regiones de mundo, pero en particular de América Latina (83,3\%). Por país de origen, las inmigrantes bolivianas, que reúnen la condición de recién llegadas en ese tiempo, aportaban el mayor número de usuarias, seguidas de ecuatorianas y paraguayas.

Entre los rasgos sociolaborales de las demandantes destacan, el nivel académico, donde se observa que el $67 \%$ contaba con estudios de bachillerato y de esa cifra, el $14 \%$ tenía estudios superiores; respecto a la situación administrativa, más de la mitad se encontraba indocumentada, es decir, en situación administrativa irregular $(52,8 \%)$. La edad media de las solicitantes se situaba en los 35 años; el 52,5\% había tenido o tenía una relación de pareja, el 33,9\% decía tener hijos, un promedio de dos, y la mayoría vivía con ellos; en cuanto a la tenencia y condiciones de vivienda, el $68,8 \%$ vivía en habitaciones alquiladas y un $14,2 \%$ vivía en alojamientos destinados a personas en situación de exclusión social, tales como pisos de acogida,

${ }^{21}$ El camino a seguir por las demandantes de empleo se planifica mediante el recorrido por un sinnúmero de centros con programas similares existentes en Madrid. En estas oficinas las usuarias depositan su currículo y se entrevistan con un técnico/a de empleo que determina el tipo de oferta a la que pueden ajustarse de acuerdo con su perfil. 
albergues y hostales. Por último, la duración media de antigüedad en España se situaba ligeramente por debajo del año y medio.

Un aspecto a destacar en relación con la biografía personal de las mujeres demandantes es el hecho de que tener hijos condiciona extraordinariamente sus posibilidades de acceso al empleo; como señalan las usuarias, el hecho de no tener hijos, el tenerlos en el país de origen e, incluso, el no tener una vida familiar "al uso", incrementa su empleabilidad. Las solicitantes de empleo adaptan su perfil a tales exigencias, de manera que, como resultado, el 53,7\% dice no tener pareja, sólo el $48 \%$ dice tener hijos y, entre estas últimas, el $41,5 \%$ se identifica como soltera, viuda, separada o divorciada; es decir, que la situación familiar y el número de hijos se invisibilizan y se adecúan a la oferta para ser contratadas. Entre las que afirman no tener hijos, el $63 \%$ se encuentra indocumentada, lo que conduce a pensar que posiblemente si tienen hijos, éstos se encontrarían en el país de origen, lo cual es un dato que puede obviarse a la hora de buscar trabajo. Pero, con independencia de la situación administrativa, contando con los permisos reglamentarios o no, quienes tienen a sus hijos en España, prefieren ocultar esta información porque saben que es un obstáculo para el empleo y que, en el caso de tener una oferta, su vida cotidiana se vería enfrentada a una difícil conciliación familiar. En estas circunstancias, las posibilidades de contratación se reducen y el empleo se ve limitado a trabajos por horas o de media jornada.

Para las inmigrantes ocupadas en el trabajo doméstico la perspectiva temporal es importante. El tiempo de estancia cumplido es fundamental para la movilidad laboral. Cuando transcurre sin incidencias, la ruta a seguir se concreta en la obtención de la regularización administrativa, que a su vez permitirá reagrupar a los hijos cuatro años después (Santos, 2011). Cuando la inmigrante adquiere la documentación elimina un obstáculo, pero su capacidad de aspirar a una vida normalizada se topa con otros problemas, como la tarea de reagrupar a sus hijos y luego sobrevivir con ellos en una situación difícil. Con todo, para estas trabajadoras el tiempo es un aliado indiscutible para su movilidad ocupacional. En el siguiente gráfico se recoge la evolución de la población inmigrante, usuaria del programa de empleo entre 2005 y 2009, según su situación administrativa. 


\section{Gráfico 1. Usuarias del programa de empleo. Porcentajes según su situación administrativa, regular (SAR) o irregular (SAI).}

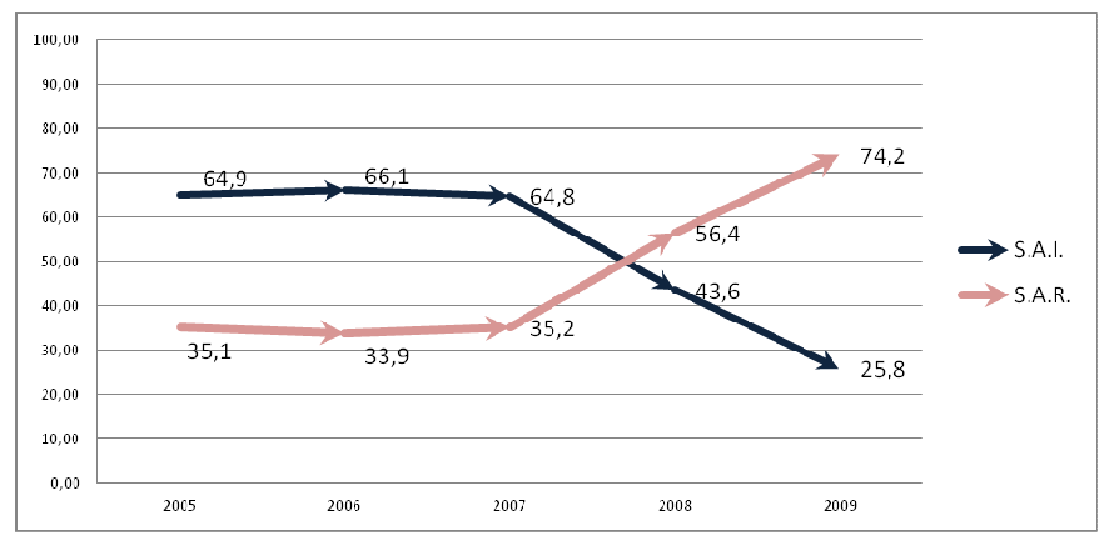

Fuente: Elaboración propia a partir de la Base de datos del programa de empleo.

Otros aspectos que la trabajadora adapta a la hora de presentar su currículo se refieren a la formación y la experiencia laboral. Los "conocimientos prácticos para el trabajo" se registran según una rutina en la que se ignoran la experiencia doméstica en sus propios hogares, tanto en el país de origen como en el de destino, la experiencia laboral, las habilidades adquiridas en empleos formales e informales en el lugar de origen, así como la formación no homologada adquirida en España. Por el contrario, la formación recibida en destino, a través de los programas con "itinerarios laborales" diseñados para su "inserción en el empleo" (donde se aprenden materias como: cuidado de personas, manejo de electrodomésticos, cocina rápida y sencilla, costumbres españolas y otras habilidades sociales) tienen mayor peso como competencias laborales para el trabajo en el hogar.

La valoración que se hace de un buen nivel educativo convierte a la demandante en mejor candidata. Las titulaciones de origen son tenidas en cuenta para valorar, pero no para contratar. Se considera que tener un alto nivel académico sirve para mostrar que se tienen habilidades sociales y capacidades para desempeñar el puesto de trabajo; es un valor añadido pero no se reconoce como un aspecto decisivo para mejorar las condiciones del contrato.

Los datos recogidos muestran que el 50,7\% de las usuarias manifiesta tener conocimientos para trabajar en los hogares, aunque el nivel académico de las inmigrantes sea superior al primario y hayan tenido experiencia laboral en otros sectores ocupacionales. A este respecto, la Encuesta Nacional de Inmigrantes (INE, 2009) arrojó resultados similares, ya que la mayoría de las entrevistadas dijo tener experiencia de trabajo en su país de origen fuera de este sector de actividad. Las usuarias, con independencia del nivel académico que presentan, afirman tener más o menos los mismos conocimientos prácticos en el ámbito del sector 
doméstico, lo que significa que todas sus competencias laborales quedan encasilladas y reducidas al saber que se les exige para trabajar en los hogares. Dicho de otra manera, lo que adquiere valor es su experiencia como ama de casa, como cuidadora, como madre, de manera que todas las demás cualificaciones o experiencias laborales quedan relegadas, cuentan para seleccionar a la candidata pero no a la hora de formalizar la relación laboral.

\subsubsection{Trayectoria laboral y expectativas de movilidad}

El itinerario laboral de las demandantes de empleo en el sector doméstico viene marcado por dos ejes principales, la experiencia ocupacional y la situación administrativa. En la siguiente tabla se recogen los recorridos laborales teniendo en cuenta, por el lado de la experiencia, el sector de actividad al que estuvieron vinculadas en el país de origen, aquel en el que han trabajado en el lugar de destino y la expectativa en relación con el sector ocupacional hacia el que querrían moverse; y, por el lado de la situación administrativa, la disponibilidad de "papeles" (situación regularizada) o la carencia de ellos (en situación de irregularidad). La articulación de ambos aspectos da lugar a diversas trayectorias: a) en ambas situaciones administrativas (regular o irregular) la experiencia en origen es baja, aunque es ligeramente mayor entre las que se encuentran indocumentadas, posiblemente porque tienen que hacer valer sus conocimientos adquiridos en origen, dado el corto periodo de residencia en España. Sin embargo, a medida que las inmigrantes van teniendo empleo, y obteniendo experiencia, la que tenían de origen se va desdibujando y se pierde conforme se alcanza la regularización. En muchos casos se produce un proceso de descualificación en relación con trabajos desempeñados con anterioridad; b) cuando las inmigrantes carecen de documentación, la experiencia laboral que se refiere en España es básicamente en servicio doméstico. Por el contrario, cuando se trata de trabajadoras regularizadas la experiencia que se refleja en las solicitudes se amplía a otros sectores de actividad, como hostelería, comercio, limpieza, trabajo asistencial en residencias y otros de baja cualificación. Con independencia de la experiencia anterior los trabajos desempeñados por las usuarias difícilmente se separan del "suelo pegajoso" ocupacional que las mantiene en los estratos más bajos de la pirámide ocupacional; y c) la pauta de movilidad más relevante es la que muestra los continuos giros de entrada y salida de las inmigrantes en el sector doméstico. Si bien un mayor tiempo de residencia en España y una coyuntura económica favorable posibilitaron su incorporación a otros sectores, el empleo en el hogar es el "refugio" al que a menudo regresan, de manera temporal en unos casos, para pivotar hacia otros nichos de trabajo, o bien para quedarse en él, porque mejoran sus condiciones laborales. Aunque sus expectativas de movilidad se orientan con frecuencia fuera del servicio doméstico, donde los trabajos tienen más garantías de formalidad, el empleo del hogar sigue siendo una meta, un lugar al que volver, donde es posible trabajar cuando en otros sectores se reducen las oportunidades. 
Tabla 3. Trayectoria laboral y expectativas de trabajo de las inmigrantes según situación administrativa

\begin{tabular}{|l|r|r|r|r|r|r|}
\hline & \multicolumn{2}{|c|}{$\begin{array}{c}\text { Experiencia de } \\
\text { trabajo en } \\
\text { origen }\end{array}$} & \multicolumn{2}{c|}{$\begin{array}{c}\text { Experiencia de } \\
\text { trabajo en } \\
\text { España }\end{array}$} & \multicolumn{2}{c|}{$\begin{array}{c}\text { Expectativas de } \\
\text { trabajo en } \\
\text { España }\end{array}$} \\
\hline Sectores de actividades & Regular & $\begin{array}{c}\text { Irregu- } \\
\text { lar }\end{array}$ & Regular & \multicolumn{1}{|l}{$\begin{array}{c}\text { Irregu- } \\
\text { lar }\end{array}$} & Regular & \multicolumn{1}{|c|}{$\begin{array}{c}\text { Irregu- } \\
\text { lar }\end{array}$} \\
\hline $\begin{array}{l}\text { Trabajos dentro del hogar } \\
\text { (limpieza, cuidados, tareas } \\
\text { domésticas) }\end{array}$ & 2,2 & 10,0 & 86,1 & 77,6 & 72,4 & 93,2 \\
\hline Residencias y limpieza & 0,4 & 0,9 & 10,6 & 2,7 & 36,5 & 31,6 \\
\hline Agricultura & 0,2 & 0,2 & 1,9 & 1,5 & 0,1 & 0,2 \\
\hline Salud, sanidad & 0,9 & 2,2 & 5,6 & 2,9 & 1,0 & 1,0 \\
\hline Industria manufacturera & 0,8 & 1,5 & 4,5 & 2,8 & 2,5 & 0,2 \\
\hline Trabajos administrativos & 1,9 & 5,2 & 6,7 & 5,5 & 7,4 & 1,5 \\
\hline Hostelería y restauración & 1,3 & 2,7 & 28,3 & 13,3 & 19,0 & 7,7 \\
\hline Comercio & 3,1 & 7,9 & 17,9 & 9,3 & 14,8 & 3,0 \\
\hline Otros trabajos cualificados & 0,7 & 2,2 & 0,1 & 0,2 & 1,2 & 0,7 \\
\hline Otros & 1,8 & 4,6 & 32,9 & 19,2 & 18,6 & 7,0 \\
\hline
\end{tabular}

Nota: Respuesta múltiple.

Fuente: Elaboración propia a partir de la Base de datos del programa de empleo.

Como se observa en la tabla precedente, a pesar de la diversidad de ocupaciones realizadas con anterioridad, las inmigrantes coinciden en depositar sus expectativas laborales en el servicio doméstico principalmente, seguido del trabajo en residencias o el de limpieza fuera del hogar. Entre quienes tienen regularizada su situación en España se observa que aspiran a trabajos en hostelería, restauración y comercio.

Así pues, el servicio doméstico es un sector de actividad que funciona como un polo de atracción, que lleva a que las mujeres inmigrantes, con documentación o sin ella, lo utilicen como trampolín para dirigirse posteriormente a otras ocupaciones o como comodín para mejorar sus condiciones de trabajo en el mismo sector. La información recogida muestra que un alto porcentaje de mujeres que ha salido del sector doméstico vuelve a él cuando se encuentra ante situaciones de adversidad, en su vida familiar, pérdida de empleo o etapa de renovación de documentos. Se genera entonces un círculo vicioso en el que interviene, entre otros factores, el tiempo requerido para regularizar la situación administrativa, como parte del engranaje institucional que conduce y reconduce a las trabajadoras al sector doméstico, quedando atrapadas en él y dificultando su movilidad. 


\subsubsection{Los hogares ajustan la demanda}

Los hogares empleadores utilizan los programas de empleo como una herramienta que les permite solucionar, con ciertas garantías, las necesidades de cuidado familiar o de realización de tareas domésticas que se les presentan. De esta manera externalizan el trabajo doméstico contratando mano de obra a través de estas entidades. El procedimiento consiste en formalizar una oferta de trabajo (por teléfono), solicitando una persona, que responda al perfil ideado, de acuerdo con el trabajo a desempeñar y la capacidad económica del hogar.

El programa de empleo, como recurso de mediación laboral, está dotado de una estructura mixta: formal, a la hora de utilizar recursos institucionales para ajustar oferta y demanda; e informal, en sus prácticas para lograr el objetivo. En este sentido, sólo el $14 \%$ de los hogares que presentaron una oferta solicitan permiso de residencia y trabajo en vigor como requisito para contratar.

El perfil requerido por los hogares se compone de una serie de requisitos y exigencias que, a menudo, van más allá de las condiciones que se pactan en una relación contractual formal. En la tabla que se muestra a continuación se expone la relación de competencias laborales complementarias que con frecuencia acompañan a los requisitos básicos para el desempeño del trabajo. Generalmente no se hacen explícitas sino que se expresan mediante palabras o narraciones en las que debe sobreentenderse la intencionalidad, tal y como se observa en la relación siguiente:

\section{Tabla 4. Relación de competencias laborales explícitas e implícitas contenidas en las ofertas}

\begin{tabular}{|l|l|}
\hline \multicolumn{1}{|c|}{ Requisito } & \multicolumn{1}{c|}{ Requerimiento implícito } \\
\hline Una nacionalidad & $\begin{array}{l}\text { Afinidad cultural y/o estereotipos en relación con nacio- } \\
\text { nalidades concretas }\end{array}$ \\
\hline Dominio de algún idioma & Enseñanza o práctica de un idioma con niños \\
\hline $\begin{array}{l}\text { Conocimiento de infor- } \\
\text { mática }\end{array}$ & Enseñanza de informática y orientación escolar \\
\hline Afecto y buen trato & Cuidado de personas mayores y/o niños \\
\hline Dominio del castellano & $\begin{array}{l}\text { Que sea de un país de habla hispana y/o que no esté } \\
\text { recién llegada a España }\end{array}$ \\
\hline Capacidad de trabajo & $\begin{array}{l}\text { Que pueda resistir como interna y/o que tendrá una carga } \\
\text { laboral alta y horarios extensos }\end{array}$ \\
\hline Responsabilidad & $\begin{array}{l}\text { Que llevará prácticamente toda la gestión y las tareas de } \\
\text { la casa. }\end{array}$ \\
\hline
\end{tabular}

Fuente: Elaboración propia a partir de la Base de datos del programa de empleo. 
Para el desempeño de las funciones que debe realizar la trabajadora se contemplan, además de los requisitos relacionados con la realización del trabajo, ciertas exigencias asociadas a la forma de ser de la persona, vinculadas a rasgos personales $\mathrm{y} / \mathrm{o}$ referidas a su condición de extranjera. Algunos ejemplos seleccionados de las ofertas muestran cualidades adicionales que se desean en una empleada doméstica: que sea alta, fuerte, que tenga coche adaptado a minusvalía, disponibilidad para viajar y horaria, experiencia con niños, con mayores, que sepa cocina española, que sepa algo de costura, que planche bien, que sepa de repostería, que sepa informática, que le gusten los niños, que le gusten los perros, que sea alegre, que tenga energías, que sea respetuosa, seria, activa, paciente, ágil, rápida, dispuesta, voluntariosa, amable, que tenga buen carácter, que dé conversación, que tenga buena presencia, que sea cariñosa, educada, autónoma, espabilada, que muestre interés, que desee aprender, que no tenga hijos pequeños, que sea madre, honrada, discreta, estable emocionalmente; que sea de un determinado país (o que no lo sea), que tenga permiso de trabajo (o que no lo tenga), que tenga permiso de residencia y no de trabajo, que lleve poco tiempo en España (o que lleve mucho), que no sea negra, que sea suramericana, que hable bien el castellano ...

En cuanto a la relación laboral, con frecuencia los hogares empleadores no muestran un claro compromiso para asumir las prestaciones legales que corresponden a la trabajadora, ni la intención de establecer una relación laboral formal. Ante la pregunta, exigida para la mediación, sobre la formalización del contrato, la respuesta es muchas veces ambigua: "según valía", "más adelante", "cuando tenga papeles", "lo arreglaré con la empleada", etc.

Asimismo, las ofertas dejan traslucir el uso abusivo que se hace de la situación de irregularidad administrativa de las candidatas. Cuando se pregunta a los empleadores por la voluntad de hacer una oferta de trabajo, el 98,6\% dice no asumir compromiso alguno para gestionar el permiso de trabajo de la empleada, ni su regularización. Las respuestas a estas cuestiones son imprecisas: "más adelante", "ya veremos", "según valía". Este hecho confirma lo ya apuntado anteriormente, en el sentido de que la situación administrativa irregular puede incrementar la empleabilidad de las candidatas. A su vez, la naturaleza de las respuestas pone de relieve la vulnerabilidad a la que la trabajadora queda expuesta con respecto a la defensa de sus derechos laborales.

La labor de intermediación de los programas de empleo no asegura el cumplimiento de la legalidad en relación con las condiciones laborales. No hay mecanismos que exijan un compromiso a los hogares empleadores para cumplir con los derechos establecidos. Desde este punto de vista se puede decir que, si bien muchas inmigrantes se encuentran en una situación administrativa irregular, buena parte de los empleos en los hogares no cumplen las condiciones laborales formales, por lo que se encontrarían, asimismo, en situación de empleadores irregulares. De hecho, solamente un $13 \%$ de las ofertas constatan el compromiso de cumplir con las condiciones laborales recogidas en la ley.

Por otra parte, en el proceso de mediación, así como en la propia relación laboral, se ponen de manifiesto las relaciones de género que subyacen en el servicio 
doméstico; se trata de una actividad feminizada donde, no sólo las usuarias sino también la mayor parte de los empleadores son mujeres. En las ofertas analizadas se reproduce el estereotipo de que es la mujer quien lleva a cabo las gestiones oportunas para buscar y resolver las tareas del hogar. En el programa de empleo que estudiamos, en el $81 \%$ de los casos es una mujer quien formaliza la oferta.

\section{A modo de conclusión. Elementos para un debate sobre la sostenibilidad del modelo basado en el servicio doméstico inmigrante}

De los aspectos tratados destacamos algunos aspectos que consideramos relevantes; en primer lugar, la necesidad de analizar el servicio doméstico inmigrante desde una perspectiva holística, en la que se tengan en cuenta los contextos estructurales, laborales, normativos e institucionales, en los que se produce este trabajo y, en relación con los programas de acceso al empleo, los aspectos relativos a los colectivos demandantes, formación, cualificación, trayectorias y expectativas laborales.

En segundo lugar, merece la pena señalar que el servicio doméstico se nutre de una población trabajadora de bajo coste, por su género y su condición extranjera. Sin embargo, junto a la reivindicación de mejora salarial en el sector aflora un conflicto de intereses (Razavi, 2007:13), entre las aspiraciones de las trabajadoras y la capacidad de maniobra de las empleadoras, muchas veces personas mayores de bajo poder adquisitivo. La resolución de este dilema enfrenta el derecho al cuidado con la exigencia de derechos laborales compatibles con el trabajo decente. Una mejora sustancial del salario de las empleadas domésticas y cuidadoras conllevaría la imposibilidad de acceso al servicio doméstico para muchas personas mayores con escasos recursos, mientras que el mantenimiento del empleo doméstico de bajo coste conduce a la precariedad laboral y la desigualdad social.

En tercer lugar, con respecto a las expectativas de movilidad de las inmigrantes del servicio doméstico hacia otros sectores menos estigmatizados y con mejores condiciones laborales, se constata que su margen de acción resulta más reducido que el de otros trabajadores. En este sentido, la trayectoria laboral de las mujeres inmigrantes es una trayectoria aplazada, porque el sector donde se mueven prioritariamente hace las veces de trampolín y de tela de araña. De trampolín, porque se convierte en el punto de partida que les permitirá dar el salto a otros sectores, al menos formalmente. De tela de araña, porque diversos factores, como la ruptura con su trayectoria laboral pasada, la falta de oportunidades para cualificarse, las condiciones personales y familiares, los tiempos para las gestiones administrativas, la normativa en materia de extranjería y, ahora, las consecuencias de la crisis económica, reducen su capacidad competitiva para acceder a otros sectores de actividad. De ahí que el servicio doméstico se convierta en un polo de atracción debido a su elevado grado de informalidad, lo que deja un margen amplio de acción para interpretar la relación laboral. 
Sin embargo, tras la observación de los datos sobre movilidad y expectativas laborales y, en la medida que distintas cohortes de inmigrantes van dando el salto a su regularización y a otros sectores de ocupación, es decir, ya no están disponibles para el empleo doméstico, surge un interrogante en relación a quién cubrirá estos puestos de trabajo, ¿quiénes serán las personas llamadas a ocupar estos nichos laborales en el futuro?

En cuarto lugar, con respecto a la labor de mediación para el acceso al empleo de colectivos socialmente vulnerables surgen algunas incógnitas. Se constata que las migrantes acuden a estas instituciones de intermediación laboral porque, frente a otras entidades, como los servicios públicos de empleo, estos programas llevan a cabo acciones de intermediación de carácter semiformal. Ahora bien, estos programas, en la medida que son instrumentos institucionales, ¿no deberían asegurar una gestión de ofertas y demandas formalizada? De la misma manera, ¿no deberían, establecer mecanismos de intermediación y seguimiento que garantizaran el ejercicio de los derechos laborales desde el inicio de la relación laboral hasta su extinción?

Y, por último, la estrategia de realización del trabajo doméstico remunerado por mano de obra (femenina) inmigrante refleja dos tipos de fracasos en relación con la organización social del cuidado; por un lado, supone una deficiencia del modelo de bienestar, porque tal opción refuerza el familiarismo y representa la desestatalización, por la ausencia de respuesta a una demanda social. Por otro lado, el empleo doméstico afecta a las relaciones de género y pone de manifiesto los desequilibrios de poder en este ámbito. En el momento en que los hogares deciden contratar a una mujer, para hacerse cargo de las tareas que tradicionalmente desempeñaban las amas de casa, se revela el fracaso de la negociación por la igualdad (Gregorio, 1998; Mestre, 2002). El servicio doméstico, lejos de transformar las relaciones de poder en el hogar y en la sociedad reproduce el estereotipo de género y la desigualdad social, ya que deriva hacia un tercer sujeto subordinado (una mujer inmigrante) la solución de conflictos de índole familiar (ausencia de conciliación) y de carácter social (carencia de servicios y prestaciones públicas). Este doble fracaso afecta a las condiciones laborales del empleo doméstico. El sector recurre a mujeres que se adecuan a un modelo patriarcal trasnochado, pero atemporal, en relación con los cambios sociales y los logros conseguidos por las mujeres de los países desarrollados. Es decir, si las mujeres autóctonas asumían en el pasado la carga del cuidado de la familia, viendo ensalzada su labor, ya que se las revestía de virtudes como la abnegación, el sacrificio y la capacidad de resistencia, entre otras, las mujeres inmigrantes que las han sustituido no necesariamente cuentan con esos valores y cualidades pero se ven empujadas a adquirirlos en el proceso de incorporación al mercado de trabajo doméstico y a reforzarlos e institucionalizarlos a medida que orientan y reorientan su currículo profesional hacia este sector de ocupación. 


\section{Bibliografía}

Anderson, B. (2000). Doing the Dirty Work? The Global Politics of Domestic Labour. London: Zed Books.

Banyuls J., Cano, E., Picher, J. V., Sánchez, A. (2002/2003). Empleo informal y precariedad laboral: las empleadas de hogar. Sociología del Trabajo, Vol.47, 75-105.

Budig, M. J.; Misra, J. (2010). Los salarios de la economía del cuidado en comparación internacional. Revista Internacional del Trabajo, Vol. 119, Núm. 4, 489-510.

Cachón Rodríguez, L. (2009). La «España inmigrante»: marco discriminatorio, mercado de trabajo y políticas de integración. Barcelona: Anthropos.

Caparrós, A.; Navarro, M. L. (2010). Movilidad ocupacional de los inmigrantes en España. Investigaciones de economía de la educación, Volumen 5, 873-890.

Carrasco, C., Borderías, C., Torns, T. (2011). Introducción. El trabajo de cuidados: antecedentes históricos y debates actuales. En C. Carrasco, C. Borderías y T. Torns (eds.), El trabajo de cuidados. Historia, teoría y políticas (pp 13-95). Madrid: La Catarata.

Centro de Estudios Económicos Tomillo (2005). La presencia de las mujeres en el empleo irregular (Con especial atención a las empleadas de hogar). Madrid: Instituto de la Mujer. Consulta 3 de noviembre 2011 (www.inmujer.es).

Colectivo IOÉ (1990). El servicio doméstico en España entre el trabajo invisible y la economía sumergida. Madrid: J.O.C.-E.

García Sainz, C. (2011). Contexto social y económico del trabajo doméstico remunerado. Modelos de bienestar y mercados laborales. En C. García Sainz (ed.), Inmigrantes en el servicio doméstico. Determinantes sociales, jurídicos e institucionales en la reorganización del sector doméstico (pp 15-76). Madrid: Talasa.

Ghai, D. (2003). Trabajo decente. Conceptos e indicadores. Revista Internacional del Trabajo, Vol. 122, Núm. 2, 125-160.

Gómez Millán, M. J. (2011). Colectivos destinatarios de las políticas selectivas de empleo. Sevilla: Ediciones Laborum. 
Gregorio Gil, C. (1998). Migración femenina. Su impacto en las relaciones de género. Madrid: Narcea.

INE (2009). Encuesta Nacional de Inmigrantes 2007: una monografía. Consulta 1 de febrero 2010 (www.ine.es).

INE (2010). Encuesta de estructura salarial. Consulta 20 de febrero 2013 (www.ine.es).

INE (varias fechas). Encuesta de Población Activa. (www.ine.es).

Liebig, T. (2009). Jobs for Inmigrants. Labour market integration in Norway. OECD Social, Employment and Migration Working Papers, núm. 94. París: OECD Publishing.

Martín Artiles, A., López Roldán, P., Molina, O., Moreno, S. (2011). Trayectorias laborales y asimilación ocupacional de la inmigración. Sociología del trabajo, Vol. 72, 41-62.

Mestre Mestre, R. (2002). Dea ex Machina. Trabajadoras migrantes y negociación de la igualdad en lo doméstico. Cuadernos de Geografia, Vol. 72: 191-206.

Noya Miranda, J. (2004). Inmigración, mercado de trabajo y Estado de Bienestar. Debate científico-político y comparación internacional. En A. Izquierdo Escribano, Inmigración, mercado de trabajo y protección social en España (pp 45-98). Madrid: Consejo Económico y Social.

OIT (2007). Marco multilateral de la OIT para las migraciones laborales. Principios y directrices no vinculantes para el enfoque de las migraciones laborales basado en los derechos. Ginebra: Oficina Internacional del Trabajo.

OIT (2011). Convenio $n^{\circ} 189$ sobre el Trabajo Decente para las Trabajadoras y los Trabajadores Domésticos. Consulta 20 de octubre 2013 http://www.ilo.org/dyn/normlex/es/f?p=1000:12100:0::NO::P12100_ILO_CODE:C 189

OIT (2011). Recomendación $n^{\circ} 201$ sobre el Trabajo Decente para las Trabajadoras y los Trabajadores Domésticos. Consulta 20 de octubre 2013 http://www.ilo.org/dyn/normlex/es/f?p=NORMLEXPUB:12100:0::NO:12100:P 12100_ILO_CODE:R201

OIT (2013). Domestic Workers Across The World: Global and Regional Statistics At The Extent Of Legal Protection. Consulta 21 de enero 2013 (http://www.ilo.org/wcmsp5/groups/public/---dgreports/---dcomm/--pub1/documents/publication/wcms_173363.pdf 
Pla Julián, I. (Coord.) (2008). Luces y sombras del recurso al empleo de hogar. Valencia: Universidad de Valencia.

Pla-Julián, I., Giménez-Moreno, R. (2012). Deficiencies and Limitations on Current Household Employment in Spain. Journal of Social Sciences 33 (3): 323-332. Consulta 4 de enero 2013 (http://www.krepublishers.com/02-Journals/JSS/JSS33-0-000-12-Web/JSS-33-3-000-12-Abst-PDF/JSS-33-3-323-12-1410-PlaJulian/JSS-33-3-323-12-1410-Pla-Julian-Tx[6].pdf).

Prieto. C. (Coord.); Arnal, M.; Caprile, M.; Potrony, J. (2009). La calidad del empleo en España: una aproximación teórica y empirica. Madrid: Ministerio de Trabajo e Inmigración.

Razavi, S. (2007). The Political and Social Economy of Care in a Development Context: Conceptual Issues, Research Questions and Policy Options. Ginebra:

Razavi, S., Saab, S. (2010). Mucho trabajo y poco salario. Perspectiva internacional de los trabajadores de cuidado. Revista Internacional del Trabajo, .Vol. 119, Núm. 4, 449-467.

Recio, A. (1999). La segmentación del mercado laboral en España. En F. Miguélez Y C. Prieto (dir. y coord.): Las relaciones de empleo en España (pp. 125-150). Madrid: Siglo XXI.

Salazar Parreñas, R. (2001). Servants of Globalization. Women, migration and domestic work. Stanford: Stanford University Press.

Salido Cortés, O. (2008). Desigualdad y pobreza. En J.J. González y M. Requena (eds.), Tres décadas de cambio social en España (pp. 205-240). Madrid: Alianza.

Santos Pérez, M. L. (2011). El trasfondo normativo en relación con el empleo inmigrante. El caso específico del empleo doméstico. En C. García Sainz (ed.), Inmigrantes en el servicio doméstico. Determinantes sociales, jurídicos e institucionales en la reorganización del sector doméstico (pp. 77-108). Madrid: Talasa.

Sassen, S. (2010). Las nuevas geografías globales: formación de la oferta de mano de obra y nuevos regímenes de empleo. En S. Montaño Virreira y C. Calderón Magaña (Coords.), El cuidado en acción. Entre el derecho y el trabajo (pp. 197219). Santiago de Chile: CEPAL.

Sen, A. (2004). Nuevo examen de la desigualdad. Madrid: Alianza.

Solé Puig, C.; Parella Rubio, S. et al (2008). Las trayectorias sociales de las mujeres inmigrantes no comunitarias en España. Factores explicativos de la diversifica- 
ción de la movilidad laboral intrageneracional, Informe de investigación. Madrid: Instituto de la Mujer.

Standing, G. (2003). El trabajo asistencial: hacia la superación de la inseguridad y la negación. En M. Daly (comp.), El trabajo asistencial. En busca de la seguridad (pp. 41-63). Madrid: Ministerio de Trabajo y Asuntos Sociales.

Stiglitz, J. E. (2009). Crisis mundial, protección social y empleo. Revista Internacional del Trabajo, Vol. 128, Núm. 1-2, 1-15.

Stiglitz, J. E. (2012). El precio de la desigualdad. El 1\% de la población tiene lo que el 99\% necesita. Madrid: Taurus.

United Nations, UNRISD. Consulta 16 de octubre 2012

(http://www.unrisd.org/80256B3C005BCCF9/(httpAuxPages)/2DBE6A93350A778

3C12573240036D5A0/\$file/Razavi-paper.pdf).

Valencia Olivero, N. Y. (2011). Acción institucional y movilidad ocupacional de las mujeres inmigrantes en Madrid. En C. García Sainz (ed.), Inmigrantes en el servicio doméstico. Determinantes sociales, jurídicos e institucionales en la reorganización del sector doméstico (pp. 109-192). Madrid: Talasa.

Zimmerman, M. K.; Litt, J. S.; Bose, C. (2006). Global Dimensions of Gender and Carework. Stanford: Stanford University Press. 